\begin{tabular}{|c|c|}
\hline 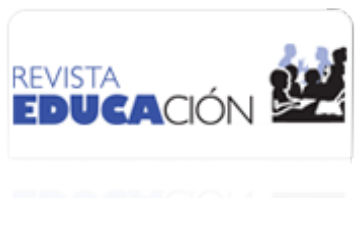 & $\begin{array}{l}\text { Revista Educación } \\
\text { ISSN: 0379-7082 } \\
\text { ISSN: } 2215-2644 \\
\text { revedu@gmail.com } \\
\text { Universidad de Costa Rica } \\
\text { Costa Rica }\end{array}$ \\
\hline
\end{tabular}

\title{
Educación y derechos humanos en Chile, una relación necesaria
}

\author{
Álvarez-Bravo, Paulo \\ Educación y derechos humanos en Chile, una relación necesaria [1] \\ Revista Educación, vol. 43, núm. 1, 2019 \\ Universidad de Costa Rica, Costa Rica \\ Disponible en: http://www.redalyc.org/articulo.oa?id=44057415026 \\ DOI: https://doi.org/10.15517/revedu.v43i1.29966
}

Esta obra está bajo una Licencia Creative Commons Atribución-NoComercial-SinDerivar 3.0 Internacional. 


\title{
Educación y derechos humanos en Chile, una relación necesaria ${ }^{[1]}$
}

\author{
Education and Human Rights in Chile, a necessary relationship
}

Paulo Álvarez-Bravo

Universidad Metropolitana de Ciencias de la Educación,

Chile

pauloalvabra@gmail.com

(D) http://orcid.org/0000-0002-3881-7978

DOI: https://doi.org/10.15517/revedu.v43i1.29966

\author{
Redalyc: http://www.redalyc.org/articulo.oa?id=44057415026
}

\author{
Recepción: 07 Julio 2017 \\ Aprobación: 09 Diciembre 2018
}

\begin{abstract}
Resumen:
Este ensayo tiene como objetivo fundamental levantar una reflexión en torno a la producción de sentidos que la educación y los derechos humanos tienen en la sociedad chilena, en la construcción del sistema y en la vivencia del día a día. Para eso habla en primer lugar de la educación, y en segundo lugar de los derechos humanos, con la idea de construir una metodología basada en el diálogo en donde la reflexividad y la crítica tengan lugar. Estas páginas sostienen la tesis de que la educación y los derechos humanos tienen una relación sinérgica y recíprocamente enriquecedora, pues apuntan a cultivar la experiencia humanizadora con la cual se constituye la vida del ser humano. Sin embargo, en muchos lugares de América Latina, como en Chile, la relación educación y derechos humanos, producto de las condiciones económicas, socioculturales y políticas fraguadas en los últimos cuarenta años, no han favorecido, sino como excepción, a su construcción, producto del divorcio en cuanto a los sentidos y perspectivas de un país hilvanado con la aguja del neoliberalismo. Como conclusión, se subraya la importancia de la relación entre educación y derechos humanos como sustento no solo de un currículum, sino del vínculo pedagógico como insumo crítico y como una forma afectiva, siempre poderosa, para construir acervos éticos y culturales que custodien y enriquezcan las relaciones humanas.
\end{abstract}

Palabras Clave: Educación, Neoliberalismo, Derechos Humanos, Pedagogía, Cultura.

\section{Abstract:}

This essay has as its fundamental aim to raise awareness on the production of senses that education and human rights have in Chilean society, in the construction of the system and in the everyday experience. For that reason, it speaks firstly about education, and secondly about human rights, with the idea of constructing a methodology based on dialogue, where reflexivity and criticism take place. These pages support the thesis that education and human rights have a synergistic and reciprocally enriching relationship because the aim is to cultivate the humanizing experience in which the human being's life is constituted. However, in many places in Latin America, as in Chile, the relationship between education and human rights, as a product of the economic, sociocultural and political conditions carried out in the last forty years, has not favored the construction of this system. This has been an exception and a product of the divorce between the senses and the perspectives of a country stitched with the needle of neoliberalism. As a conclusion, the importance of the relationship between education and human rights is underlined as a basis not only of a curriculum, but also of the pedagogical link as a critical input and as an affective, always powerful, form to construct ethical and cultural heritage that safeguard and enrich human relations.

KEYWORDs: Education, Neoliberalism, Human Rights, Pedagogy, Culture.

\section{INTRODUCCIÓN}

Hechos históricos que marcan la trayectoria de Chile en los últimos cincuenta años, se asumen en este ensayo como hebras que articulan ideas y fuerzas, y que dan pábulo a una serie de aspectos los cuales no terminan de eclosionar tanto en lo que se refiere a la educación como a los derechos humanos.

En la primera parte de este ensayo, se expone el tema de la educación como un campo de disputa y de poder, como la herramienta catalizadora más concreta del capital humano de un país. Su configuración da cuenta de ser una temática en permanente tensión donde se forma lo cultural y lo político, lo social y lo económico, interactúan tocando los elementos celulares que le dan vida a la existencia. Desde experiencias que abonan por procesos integrales, no necesariamente logrados, el tema de la educación va siendo pensado desde el lugar 
que ha ido ocupando en Chile y del cual podría proyectar sus desafíos de futuro. El ensayo habla que desde la instalación del sistema neoliberal en Chile es clara la reducción de la importancia del Estado como garante de calidad de vida, versus la relevancia del mercado en temas alguna vez considerados como derechos sociales entre los que se cuenta la educación. Desde ahí, se expone que la educación ha visto erosionada los acervos que alguna vez pudieron identificar su sentido haciendo alusión a la importancia de justicia social, la eticidad de las acciones y la relevancia de encontrar un camino común con los derechos humanos que junto a potenciar su fundamento podrían configurar un hacer pedagógico práctico y sinérgico.

En la segunda parte del ensayo, el tema de los derechos humanos es tratado desde la relevancia de su significado y sentido para la sociedad en general y para la educación en particular, dejando claro que su envergadura ha sido producto de un laborioso proceso histórico que puede tanto solapar su contenido como abusar de su peso. Hechos acaecidos en el mundo, hechos ocurridos en Chile durante la dictadura cívico-militar y que parcialmente continúan ocurriendo, son expuestos como ejemplos concretos de la contradictoria capacidad humana de amar y matar. Se estima que asumiendo ello, la educación puede jugar un papel central y recíproco con los derechos humanos sobre todo a la hora de comprender y proyectar un compromiso ético.

\section{Educación en Chile}

Durante el siglo XX en Chile, el acceso de las personas a los diferentes eslabones que componían el sistema educativo fue creciendo de la mano del Estado, la Iglesia, la Sociedad de Instrucción Primaria -SIP(financiada por privados), y también de iniciativas socioorganizativas nacidas del movimiento obrero. Con cierta incredulidad, se sabe por ejemplo, que el número de mujeres inscritas en el sistema educacional en las primeras décadas del siglo XX era muy similar al de varones (Salazar, 1988), sin embargo, la continuidad de estudios se restringía drásticamente favoreciendo a los sectores de mejores condiciones económicas y, desde el punto de vista de género, a los hombres por sobre las mujeres. Comparativamente con la actualidad, el ingreso a la educación formal llegaba a menor cantidad de personas, pero al igual que hoy muchos de ellos abandonan el eslabón de estudios en alguna parte.

En términos generales, los procesos formativos de estudio establecían mallas curriculares rígidas e institucionales en medio de un proceso de escolarización creciente que, desde la mitad de la década de los sesenta, presenta procesos alternativos liderados por la cosmovisión de una educación basada en el acervo del hombre común y corriente con teorías inspiradoras de libertad y esperanza asociadas a Paulo Freire y la educación popular. Se trataba de procesos alternativos de promoción y desarrollo variados, según el tipo de condición o labor de las personas y en donde el estudiantado y el cuerpo docente solían compartir un escenario modesto convertido en una sala de clases y un mismo proyecto humano y político; convertirse en mejores seres humanos para construir una mejor sociedad.

Los relatos de nuestros mayores dicen que era una educación más centrada en la necesidad de desempeñarse en algún oficio, de corte profundamente machista, jerárquica y asimétrica en su constitución de género; no obstante, valoraba el espacio educacional como oportunidad y al profesor(a) como un agente central en la formación. La sociedad chilena podía, como hoy, pagar un sueldo de miseria al profesorado, pero pocos se atrevían a cuestionar la fortaleza ética y la profunda nobleza de sus inspiraciones. Hoy en cambio, eso no sucede o se relativiza, quizá porque el profesor(a) es visto como un servidor de un artículo de consumo que obedece a las directrices de un establecimiento-empresa, o porque el sistema terciarizó su vocación, o porque producto de experiencias concretas de abuso de poder (Ortega y Güell, 2004) es parte de la desconfianza generalizada que afecta las relaciones humanas y la alteridad social.

En el contexto de un Chile pobre y empobrecido, entre las décadas del treinta al setenta, la educación era asumida por la población como la plataforma básica de cambio y movilidad social. En ella, los sectores históricamente excluidos de los beneficios y oportunidades del sistema, podían tener una ocasión entre no 
muchas de desarrollo. Sin embargo, la educación superior nunca pudo integrar realmente a los proletarios ni a los sectores populares a no ser como excepción. Los que sí se incorporaban a ella, sentían sobre su cuerpo una responsabilidad, no importando mucho a qué sector social pertenecían. El profesor chileno Humberto Maturana (1997), recordaba que cuando era estudiante de medicina en la Universidad de Chile sentía haber estudiado:

Para devolver al país lo que había recibido de él; estaba inmerso en un proyecto de responsabilidad social, era partícipe de la construcción de un país en el cual uno escucha continuamente una conversación sobre el bienestar de la comunidad nación que uno mismo contribuía a construir siendo miembro de ella. No era yo el único, dentro de la diversidad de identidades políticas, había un propósito común (...) un compromiso explícito o implícito, de realizar la tarea fundamental de acabar con la pobreza, con el sufrimiento, con las desigualdades, con los abusos. (p. 12)

Hoy esto ocurre poco, si es que ocurre. El sistema de mercado ha convertido con éxito a la educación en objeto de consumo. El poder o no estudiar y la calidad educativa que podría recibir una persona tiene en el poder adquisitivo un factor específico de peso que ha exacerbado las históricas diferencias que la educación ha garantizado. El Estado se comporta como un distribuidor de recursos que atrapa a las universidades en el vaivén del mercado. Un sistema educacional más comprometido con las definiciones del modelo económico imperante, en el contexto de un país subdesarrollado como Chile podría abonar exclusión más que integración. La erosión de pautas sensibles con las necesidades y problemáticas de carácter cualitativo que se requieren es tratada con el prisma de la competencia y la eficacia. Lo anterior no solo es un problema de falta de perspectiva o un cambio de enfoque que afecta lo funcional si no que, con el tiempo, tocará, como de hecho ya lo hace, la trama cultural con que se teje el presente y las expectativas de vida de las personas.

Los estudiantes de ayer, como Humberto Maturana, tenían más posibilidades que los de hoy de sentir un compromiso con lo público y con las necesidades y sufrimientos de su pueblo. Hoy, al terminar la juventud el sistema escolar de enseñanza secundaria cruza el umbral hacia institutos de formación técnica, universidades, tradicionales y privadas, y se encuentran con el patio trasero del colegio que pretendieron dejar. Sin embargo, se exige de ellos muchas más cosas que antes, en un mundo ahora más voraz, global e inmediato que tiene pendiente viejos problemas como la pobreza y la exclusión, que entiende con dificultad y no sin razón, de otros dilemas que se actualizan como la interculturalidad y las relaciones de género y que se siente francamente desconcertado con nuevas realidades como la inmigración extranjera y los fundamentalismos. Un sistema despiadadamente competitivo, como el descrito, que fortalece lo individual sobre lo social y lo pragmático sobre lo pedagógico, tiene mucho para relativizar el valor de la educación.

No decimos nada nuevo, cualquier persona mínimamente atenta al devenir de Chile puede decir lo que hasta ahora se ha escrito y de mejor forma. Quizá sea hora de recordar algo subyacente al propio proceso de formación; esta no compete exclusivamente a los educandos ni a los educadores, a un jardín de infantes, escuela, liceo o universidad, le compete a todos los que forman parte de una comunidad social. Es por eso la educación debería competerle al país entero. Cabe recordar lo que emergió en Santiago de Chile con la toma de la Pontificia Universidad Católica en 1967, en las calles de París en 1968, el Cordobazo en Argentina y la triste memoria de Tlatelolco en ciudad de México ese mismo año, ¿Qué nos dicen esos hechos? Nos dicen que la educación, así como la cultura, no es una sola cosa ni depende de un solo agente. Aquí, quiéralo o no, están todos y no se produce solo en la institucionalidad, aunque este momento sea tan difícil para demostrar lo contrario. Como las mejores o más trascendentales cosas de la vida, es en la vida familiar, también entre los amigos, donde nuestros fundamentos humanos se constituyen. Sobre todo, más que cualquier cosa, la educación se trata de ayudarnos a convertirnos en mejores seres humanos. La educación debiese ser siempre una construcción amorosa, una relación afectiva que hace del amor su sustento primero para que lo demás brote con la intensidad necesaria en el reconocimiento y proyección del otro.

Esa alteridad brota y se cultiva. Ante la pegunta de un periodista del diario El País sobre qué es la cultura, el escritor Claudio Magris decía que la cultura es la capacidad crítica de juzgar y de juzgarse, de no creerse el centro del mundo, de conseguir relacionarse. Hace falta una educación que se enseñe sin querer enseñar. Mis 
padres nunca me dijeron que no debía ser racista como tampoco que no se comía en el cuarto de baño, pero el modo de comportarse en casa hacía impensable una cosa o la otra. Y también aprendí en la escuela otra cosa fundamental. A reír con las cosas que amaba y respetaba, y a amar las cosas que me hacen reír. (Ordaz, 2014)

No decimos nada nuevo, por muy desgastada y mala propaganda que tenga el nombre, escribámoslo. El fundamento humano de cualquier relación, así como también en la educación es el amor, desde ahí se podría mirar con más esperanza la derrota y con más fortaleza el desamparo que produce la sociedad neoliberal, que capa a capa se superpone uno sobre el otro, sin dejar de ser aplastado por el abrumador peso del poder dominante en donde la educación posee un rol central:

En la variable educativa, el capital cultural, es un principio de diferenciación casi tan poderoso como el capital económico. Hay toda una nueva lógica de la lucha política que no puede comprenderse si no se tiene en mente la distribución del capital cultural y su evolución. (Bourdieu, 2014, p. 70)

La simbiosis entre mercado-educación instaladas en el ámbito pedagógico y proyectada socioculturalmente, podría ayudar a producir seres humanos que se comporten como pequeños tiranos de la cuota de poder que tienen, generando relaciones humanas donde los sentidos y sensibilidades valóricas se diluyen por la relevancia del dinero, y en donde la dimensión política y sociocultural, propia de cada persona, se vuelve sumisa ante el poder e insustancial ante el sistema. Desde ese prisma, la pobreza y el empobrecimiento sería parte del engranaje del sistema y la educación un parámetro para medir competencias y habilidades.

Este no es un salto de página, es el contexto que la educación (y la cultura) vive hoy en Chile. Ningún sistema ha logrado triunfar sin la complicidad al menos momentánea de la mayoría, sin que sus tentáculos no permeen la vida cotidiana. Y bien, si este ahora que diagnosticamos es tenaz para colocar entre nosotros el tema de la educación en clave de derechos humanos, también lo es porque el hombre y la mujer común y corriente la aceptan como proposición de presente-futuro. Un sistema basado en el éxito, la competencia, el poder, sin los otros, inevitablemente levanta soliloquios que no interlocutan, sino que asume al otro cualquiera (que a su vez es él mismo) como un no otro, una especie de producción de seres humanos convertidos o tratados como nadies.

El neoliberalismo reinante no solo ha triunfado porque puede mostrarse cierto de indicadores macroeconómicos y un flujo comercial creciente, sino porque ha provocado que las utopías sociopolíticas de un ayer no tan lejano, como la construcción de un Chile volcado a la justicia social de la década del sesenta, devenga obsoleta en pos del enriquecimiento material y el estatus individual. Desde esa perspectiva, los sueños sociales albergados en lo más íntimo de muchas personas, y por los cuales no pocos fueron asesinados, no solo se reducen, sino que generan incomprensión, lo que desde el punto de vista del presente conlleva a que se desafecten los vínculos y se esconda la fragilidad (ese inmenso tesoro que nos enseña que estamos vivos). Cuando se deja de soñar y de tener sentido del humor reducimos nuestros sueños a los programas de televisión, incluida las pausas comerciales escribía el antipoeta Nicanor Parra (1992) encargado por UNICEF, junto al grupo de música Congreso, para conmemorar la Convención Internacional de los Derechos del Niño.

Por consiguiente, en un contexto neoliberal que erosiona las utopías sociales no es extraño que brote el miedo, "Se dice que la vida no vivida es una enfermedad de la cual se puede morir.... un modo de morir antes de la muerte es el miedo. La gente muere de miedo" (Lechner, 2006, p.339), como de hecho ya ocurre. Ese miedo difumina horizontalmente su huella de deshumanidad, de vacío, de soledad sola, de profunda ignorancia. En sus últimos escritos, el profesor brasileño Paulo Freire (2014) se mostraba preocupado por la realidad que veía a fines del siglo XX en América Latina:

La educación ya no es formar, ahora es entrenar. La pedagogía crítica es un devaneo retrogrado de viejos sin rumbos que pregonan la reacción. Para mí, la lucha por hacer realidad el sueño, la utopía de la capacidad crítica, la esperanza, es la lucha para evitar la negación del sueño y de la esperanza fundada en la rabia justificada y en la acción ético-política eficaz. (p. 150) 
A partir de lo descrito, el tema de la educación gratuita y de calidad que se enuncia en la agenda púbica gubernamental puede ser parte de un discurso muy parcial, tal como sucede con el tema de la violación a los derechos humanos cometidos durante la dictadura cívico-militar chilena que es parte de una agendita política que se remece entera cuando por ahí o por allá un hecho que se creía enterrado reaparece, delatando incomodidad y evidenciando la falta de verdad y de justicia. Es la impunidad que afecta a la mayoría de los casos reconocidos en los informes de la Comisión Nacional de Verdad y Reconciliación (1991) y de la Comisión Nacional Sobre Prisión Política y Tortura (2005). Cuando así ocurre, la capacidad de receptuar a bien las demandas, como las movilizaciones a las que han dado vida el estudiantado, se cierra y son tergiversadas al enredarse en un juego político en donde el statu quo apenas se conmueve para conceder lo mínimo, tal como refleja el tema de los derechos humanos en Chile.

Los derechos humanos en Chile, como ocurre en otros lugares del continente, son tratados como un tema cerrado, pesado, siempre inoportuno para hablar y entender al país actual y al del futuro. Esa lógica corporativa, institucional y jerárquica que caracteriza al orden neoliberal imperante, corre el riesgo de continuar en la miopía que generan las estructuras reproductoras de miseria que afecta, por supuesto, con violencia inmisericorde a los de siempre, a la gente común y corriente. Paralelamente, los jóvenes no pueden, no tienen dónde encontrar insumos que les ayuden o acompañen en este proceso de búsqueda, exploración o de proyecto. No es solo la paradoja de un sistema que los inhabilita, aun cuando cumplan con las definiciones que ese sistema les exige sino que, simplemente, su condición de origen no les da lugar. Se sienten solos, pero no hay que compadecerse, históricamente han sido esos escenarios de opresión desde donde surge la fuerza activa para actuar, movilizante y creativamente a contracorriente.

Es un desastre total, desastre total escribió Nicanor Parra. Ignoramos si estaba pensando en la educación chilena, pero inevitablemente podríamos pensar que sí. Con honrosas excepciones, en donde la dignidad se hace ética, y con las reservas que implica una mirada general, se podría acudir a cualquier escuela de nuestro país, y observar las relaciones humanas de la pretendida comunidad educativa, los parámetros de evaluación, eso que llaman competencias y saberes, la llamada misión educativa y el emprendimiento escolar, y mucho de ello se vuelve, sino insustancial, un eslogan pretencioso y funcional. En vez de interconectar los colegíos y las universidades, a las personas en sus diferentes espacios y niveles educativos se opta por reforzar visiones económicas que refuerza la tendencia de privatizar no solo el acceso sino la calidad educativa. Ponderaciones emanadas desde criterios materiales podrían ayudar a diluir las relaciones personales, lo formativo y lo académico, hacía nuevas prácticas que precarizan la responsabilidad ética de la educación en pos de las definiciones de un mercado, por lo general mezquino cuando se trata de lo público. Desde ahí acciones propias del educar como reflexionar, deducir, relacionar, inferir, por nombrar algunas facetas, pensar por sí mismos y fortalecer el carácter son poco trabajados o lo son desde la visión de los vencedores.

Muestra de lo anterior son las pruebas de medición, como la Prueba de Selección Universitaria (PSU) o el Sistema de Medición de la Calidad de la Educación (SIMCE), las cuales tienen resultados penosos para los sectores excluidos a nivel local. Lo escrito se replica en el contexto internacional, donde el bajo promedio comparado de nuestro país en pruebas como el programa para la Evaluación Internacional de Alumnos (PISA), que en la medición de 2015 ubica a Chile -y a los países de América Latina- en los últimos lugares entre los países miembros de la Organización para la Cooperación y el Desarrollo Económicos (OCDE). Los resultados del año 2017 son similares, aun así Chile es el mejor evaluado en el contexto Latinoamericano. Al mismo tiempo, muchos estudiantes se molestan y frustran por expectativas que jamás encontraran en la educación superior. Quieren, dicen que quieren, ser agentes participativos del proceso educacional, quieren sentirse escuchados, aprender y adquirir destrezas, aunque pocos estén dispuestos a luchar por ellas.

El cuerpo docente, por otra parte, se deja tratar o simplemente ha naturalizado comportarse como agente siempre atento y disponible a las necesidades del alumnado. Hay aquellos que dicen incorporar sus ideas, nuevas tecnologías, teorías curriculares y didácticas de moda, pero se muestran poco capaces de interpelar qué es lo que puede estar pasando para que esta demanda de medios y recursos tenga mayor protagonismo que 
el diálogo y la reflexión. El acto de valorar, de entender, el contexto multifacético y subjetivo de las personas con quienes se construye y comparte el educar en espacios como el descrito tiende a ser soslayado. Otros profesores, en condición de alineación con los planes y programas, se vuelven verdaderos gendarmes de un sistema educativo carcelario, que ha encerrado con llaves las capacidades que la educación otorga por sí misma.

En Chile, ¿se está hablando lo mismo que en otros muchos países del mundo cuando se habla de educación? Sí y no. Sí, porque las relaciones asimétricas en educación pertenecen a muchos lugares, incluso desarrollados, como lo sostuvieran Bourdieu y Passeron (2006) en su libro Los Herederos donde levantan un análisis sobre la educación en Francia: "El sistema educativo puede asegurar la perpetuación del privilegio por el solo juego de su propia lógica” (p. 45). Pues la educación es un campo de disputa y un ejercicio de poder. Pensemos en quienes tienen la posibilidad de desplegar su vida en las oportunidades y quienes no la tienen. Pensemos en la calidad asignada para quienes mantienen una cuota de poder y aquellos que no. La educación es un escenario de disputas ideológicas, dado su papel en la formación de valores y sentidos de los educandos. Si aceptamos que es así, aceptamos que lo que hacemos como educando y educadores, como agentes de un espacio marcado por la educación, nunca es inocente. Entonces piénsese en Chile, y también se puede responder que no se habla de lo mismo que otros muchos países. Porque los chilenos se ofrecen condiciones profundamente generosas para hacer del sistema educacional una de las evidencias más profundas de desigualdad e inequidad país, lo que hipoteca su desarrollo y capacidad de integración. Kremerman (2009) afirma que "Las políticas aplicadas a partir de la década de los ochenta, acentuaron la configuración de un sistema educacional segregado según el nivel socioeconómico del alumnado. En los noventa, para asegurar cobertura, se descuidó la calidad y lentamente se dejó de hablar de educación pública”. (p.15) Brecha que se define como un verdadero apartheid educacional.

Este panorama, reflejo de la mayor parte de la educación en Chile, ha afectado sensiblemente temas importantes como el valor de lo humano. Desde el orden actual el valor, reconocimiento y formación de lo humano concluye con la hegemonía del discurso neoliberal, tal como lo afirma el sociólogo Juan Oyarzún (2017): "El recolector informal de basura solo puede adquirir valor en la medida que se inserta en la cadena de valor económico, donde parece reportar mayor validez social aportar al mercado que proclamar su dignidad inherente como sujeto de derechos" (p. 112). El valor de lo humano, asumido por el sencillo y esencial hecho de ser humano se mide por su capital humano, el valor de las emociones como fuente en donde se cobijan las esperanzas del hombre y la mujer de hoy y de mañana, el aprender a pensar, reflexionar, disentir, aceptar, respetar y respetarse, el reconocer la riqueza de la diversidad y de lo propio, como elementos identitarios constructores del cuerpo social se sopesan en la trama del mercado:

En este espacio de disputa de discursos, entendidos como lógicas de sentido, la educación, hoy por hoy, aparece más claramente como un medio de agregación de competencias individuales para el mercado, que un proceso con un fin trascendental en sí mismo y un medio para una sociedad más justa. El reconocimiento social e institucional se reduce al currículum, el rendimiento y el estatus de los individuos de manera desigual. (Oyarzún, p. 107)

Si hasta ahora hemos ayudado a que la educación se piense como panacea, hija de un lugar o de determinados sujetos, es porque lo estoy haciendo muy mal; no queremos sacralizar la educación. Educar es solo posible cuando existen las condiciones adecuadas para hacerlo, dice Juan Tedesco (2000), quien recalca:

Las condiciones materiales de vida de los alumnos son un factor fundamental del éxito educativo. Todas las mediciones sobre logros de aprendizaje y sobre desempeño educativo coinciden en señalar que los resultados están asociados al estatus social y al nivel de ingresos de las familias (p. 92-93).

Es mentira que la educación ha sido o es signo de libertad, es más bien una apuesta hacia ella y hacia lo mejor que una sociedad podría ser.

Hay que considerar que de pueblos preparadísimos y de una cultura rica en sentido como en acervo han surgido también sistemas de opresión y de muerte sistemática, como los nazis. Una educación exacerbada, seguramente en la uniformidad y la ley, en la institucionalidad y el orden enfermizo, podría ser negadora de 
la raíz contradictoria que hace a lo humano, auspiciando de esa forma la homogeneidad de pensamiento y de formas de hacer y de ser, obligando como de hecho ocurre, a un deber ser determinado. Una educación que se mira el ombligo puede caer en la institucionalización excesiva y es propensa a pensar que nada que nazca o se produzca fuera de ella tiene valor, lo cual genera el perverso efecto de contribuir a profundizar los vínculos de distinción que de por sí ya produce la educación, empobreciendo la posibilidad de diálogo, autenticidad y diversidad compartida.

La sociedad chilena, así como la Latinoamericana, alimenta los signos de distinción como una forma de relacionarse, con ello cultiva relaciones humanas que hipotecan la posibilidad de reconocerse, encontrarse e interrelacionarse. Cada grupo es un verdadero archipiélago social que parece poco dispuesto en vincularse en pos de conocer y de paso abrir las compuertas hacía la diversidad, la tolerancia y el dialogo. Una sociedad de clases hace del sesgo un modo de comportarse. El apartheid educativo que señaláramos párrafos atrás, en vez de buscar o de filtrar en pos de los otros, sella los sesgos como una especie de determinismo que marca el presente y el futuro de las personas pertenecientes a un grupo social. Tal como lo señalan los investigadores Meuss, González y Manzi (2016) para Chile, en el sentido que la vulnerabilidad de los grupos sociales desventajados en educación no es solamente un tema de recursos económicos o intelectuales, sino también un tema de color de piel y de otros estereotipos incorporados.

Todo lo señalado hasta aquí denota la relevancia de una educación que interpela su sentido y hacer, y que desde esa dirección abone una convocatoria a "la justicia social comprendida desde el reconocimiento... La justicia no se lograría solo a través de la distribución de bienes” (Silva, 2017, p. 128). Una educación que se oriente a los derechos humanos y que incorpore su acervo como práctica "Debe presentarse como una búsqueda argumentada de nuevos sentidos para la política, que coloque de relieve valores como la solidaridad, la tolerancia, la participación ciudadana" (Osorio, 2003, p. 196).

\section{DERECHOS HUMANOS}

Para la sociedad civil, incluida las comunidades educativas, no es muy evidente la relación entre educación y derechos humanos. Parece, sin embargo, una clave reflexiva para poder dar cuenta de la sociedad y país que se vive y construye, pues la condición en que se encuentran los derechos humanos podrían dar cuenta de la salud psíquica y de la capacidad de resiliencia de una sociedad, de la madurez con que asume sus dolores y traumas y de la actitud expresada en políticas públicas y gestos políticos que tengan a bien su custodia. Para lo cual sería importante replicar la definición de los derechos humanos y cómo podría estar desplegándose en Chile en el ámbito de la cultura, reflejo del patrimonio inmaterial del cual está revestido.

El artículo 26 de la Declaración Universal de los Derechos Humanos de 1948, al que Chile suscribe, dice en sus distintos incisos:

Toda persona tiene derecho a la educación (...) La educación tendrá por objeto el pleno desarrollo de la personalidad humana y el fortalecimiento del respeto a los derechos humanos y a las libertades fundamentales; favorecerá la comprensión, la tolerancia y la amistad entre todas las naciones y todos los grupos étnicos o religiosos, y promoverá el desarrollo de las actividades de las Naciones Unidas para el mantenimiento de la paz. (ONU, 1948, p. 8)

No obstante, estar consagrados por la carta fundamental, la experiencia sistemática de la violación a los cuerpos y los derechos humanos durante la dictadura cívico-militar, compone unos de los ejes que explica la dificultad del Chile actual de soberanizar sus problemáticas en pos de salir del espasmo de una conciencia desgarrada. La Constitución Política de la República de Chile (2005) protege algunos derechos fundamentales como la vida, la salud, la libertad e integridad de las personas, pero no los derechos sociales. En relación a la educación, dice "proteger la libertad de enseñanza" (Cap. III, art. $\left.19 \mathrm{~N}^{\circ} 10\right)$. Temas como los derechos humanos y la educación, más que un fundamento del hacer político y una experiencia ciudadana, asemejan una diplomática y necesaria nomenclatura del orden dominante.

Si bien nada garantiza que los derechos humanos sean absolutamente consagrados, promovidos y respetados, ni siquiera pensando en que están asegurados constitucionalmente y que son parte del currículum escolar, la educación es un medio y un fin que fundamenta, releva y promociona su sentido, pues puede colocar en perspectiva su transcurso y resguardar sus conquistas significando la tragedia que le ha dado vida. Pues, los derechos humanos y la educación son un ejercicio 
ciudadano y no una lección que algún día se termina de aprender. El cómo hacerlo es una pregunta recursiva la cual implica necesariamente abandonar el solipsismo autoritario y vertical del poder de turno, abandonar la falta de alteridad social y cultural apostando por un hacer plural que se comporta como una posibilidad de darle lugar a la utopía, tan necesaria, con que la política debiese trabajar en respuesta de lo que socialmente somos o podríamos ser.

Al hablar de derechos humanos en el siglo XXI, inmediatamente se debe considerar todo lo que se le opone; las formas de muerte en vida, la deshumanizadora acción del poder tecno-financiero y militar que parece erigir el planeta. Puede ser que el tema de la educación y su compromiso en la defensa y promoción de derechos humanos sea una acumulación de normas y palabras de buena crianza, sin mayor correspondencia ética con quiénes la declaran o dicen promoverla, pues los derechos humanos suelen ser un discurso atractivo y utilizado en el eslogan del poder.

Los derechos humanos son hijos del sistema burgués que triunfó con la revolución francesa y que entendió la democracia como un sistema apenas molesto para continuar con su hegemonía. Pero el catálogo de los derechos que son considerados como fundamentales da cuenta de una evolución, y una expansión, del concepto de ciudadanía. Para T.H. Marshall (1992) en su ya clásico libro-ensayo Ciudadanía y Clase Social "El elemento social abarca todo el espectro, desde el derecho a la seguridad y a un mínimo de bienestar económico a compartir plenamente la herencia social y compartir la vida” (p. 23). El siglo XVIII vio surgir los derechos civiles como un correlato de un concepto de ciudadanía que se limitaba a la libertad en la esfera individual. El siglo XIX, por su parte, fue testigo del surgimiento de los derechos políticos, que, permitiendo la participación en los asuntos públicos, eran reflejo de un concepto de ciudadanía entendido como derecho, justamente, a ser parte en la vida pública. Por último, durante el siglo XX, asistimos al surgimiento de los derechos sociales, que representan la última evolución en un concepto de ciudadanía que ahora, también, considera que la atribución de prestaciones sociales a los hombres y mujeres que forman parte de la comunidad política, con total independencia de su capacidad adquisitiva, es reconocimiento de la igual pertenencia a dicha comunidad y, así, reconocimiento de la misma calidad de ciudadanía. Sin embargo, "Los datos sobre ciudadanía social muestra que la mayoría de los países de América Latina exhibe severas deficiencias que afectan a importantes y, en ocasiones, mayoritarios segmentos de sus poblaciones" (PNUD, 2004, p. 119).

¿Qué caminos supone recorrer el abrirse a una reflexión respecto a educación y derechos humanos? Supone salir del individualismo exacerbado fomentado en la actualidad y hablar en plural, de la capacidad de pensar como hombres y mujeres, como seres humanos compelidos por el transcurso histórico que le toca vivir. Como docentes actuales y futuros, quienes se desempeñan no importando más el dónde o con quiénes, implica revestir de sentido y humanidad un oficio que no en pocos casos se encuentra distante de aquello. Para los futuros profesores, recalcamos que se tiene la bella posibilidad de ampliar el lenguaje humano y de proponer como cosa primera, el valor de la vida, del amor, de la condición humana, como aprendizaje posible. Los docentes, en especial los que se desempeñan cotidianamente en espacios derruidos, tienen la difícil tarea de reconocer la dignidad de los seres humanos de distintas edades que les rodean dentro de un aula, en el patio de la escuela, en el jardín, en el trayecto entre la casa y el lugar que cobija el educar y verán que al final se trataba del mismo lenguaje; de valorar, de reconocer, de hacer de la vida de los otros y la suya propia tenga valor.

Cuando parte de los países del planeta firmaron la Declaración de los Derechos Humanos (ONU, 1948) estuvieron de acuerdo en afirmar, en su artículo uno: "La libertad, la justicia y la paz en el mundo tiene por base el reconocimiento de la libertad intrínseca y de los derechos humanos iguales e inalienables de todos los miembros de la familia humana” (p.1). Aparentemente, el ser humano comprendía que nada se puede interponer a la vida y que la dignidad y valores que sustentan éticamente su existencia no pueden ni deben ser sobrepasados por ideologías, actos, ni leyes que la desconozcan. Y aunque las evidencias históricas no dejan de reproducir actos de barbarie y abuso de poder, es importante que existan marcos que resguarden los mínimos éticos de las relaciones humanas relevadas como derechos fundamentales. Es verdad que el mundo sigue estremeciéndose de horrores y transgresiones a la vida, lo cual demuestra que el valor de cualquier declaración en defensa o promoción de los derechos humanos, como siempre lo sostiene la ética. Esa ética, que siempre es política, puede tener un mejor contexto para cultivarse desde la educación porque supone un proceso de formación horizontal y polifónica, en donde la justicia social, la alteridad y la disidencia pueden ser expresadas desde la tolerancia.

Es la ética que sostuvo a Primo Levi, sobreviviente de Auschwitz, quien mientras vivió denunció la opresión y el horror, hasta que un día tomó la muerte por sus manos, quizá porque nunca pudo reponerse de la vergüenza de sentir que de eso se trataba ser humano. Es la ética de una parte no menor de los pueblos originarios que resisten la opresión y eso que el tiempo presente llama modernidad, manteniendo su sentido de libertad. Es la ética de millones de mujeres, muchas de ellas mamás, que no han aceptado la cultura de dominación machista y que han peleado no solo por una democracia política sino también por la equidad, anteponiendo su propia vida para ello. Es la ética de millones de anónimas vidas que diariamente con sus ideales, pero sobre todo con sus prácticas, dan amor.

En todo caso, no son solo los sistemas de dominación los que han optado por la muerte. Subyacente a ellos están aquellas relaciones humanas que reducen la vida basándose en el poder, ocupándolo en su beneficio exclusivo. El abuso de poder dice mucho de la educación de un pueblo, pues si es verdad que la educación es un campo de lucha ideológica y sociocultural, esta puede configurar espacios de dominación contenidos de sometimiento, manipulación y coerción. Educar no es un lujo como tampoco es una receta. 
Tampoco sería posible hablar de lo que estamos hablando sin que los movimientos que dieron vida a los derechos humanos no hubiesen persistido en la lucha o no hubiesen tenido eco para plantear la necesidad de vivirlos. La mayoría lo hizo desde la irreductible convicción que era necesario exponer su vida incluso con la muerte para reclamar por ella. En Chile, la dictadura cívico-militar llevó a que la sociedad chilena conociera los actos de barbarie más terribles en paralelo a los actos de solidaridad y dignidad más profundos. Los cerca de tres mil asesinados y detenidos desaparecidos consignados en el Informe de la Comisión Nacional de Verdad y Reconciliación (1991), "los más de cuatrocientos mil exiliados y doscientos mil torturados" (Stern, 2009) sin contar a los familiares de las víctimas, son la huella más imborrable de un sistema socialpaís que a su vez aumentó la brecha de desigualdad y cuyo sistema de privatización de lo público generó réditos privados cuantiosos y perdidas públicas abismantes. En el corazón de los cambios económicos, la violación de los cuerpos y de los derechos humanos no significó el fin de la dictadura cívico-militar, sino más bien la necesidad del propio sistema de mercado de expandirse.

La transición política chilena, está marcada por la frase "hacer justicia, en la medida de lo posible" (Aylwin, 1992, p. 414) y por las ansias de un futuro amnésico, antes que de reconocimiento por las responsabilidades en la violencia política y los atropellos a la vida. No obstante, la memoria irrumpe como sucesivas olas sobre la arena. De esa forma los derechos humanos devienen cargados de todo, a enrostrar la desidia y el vacío. Los derechos humanos no son un tema de ayer. Recordemos la reciente amonestación de la Corte Interamericana de Derechos Humanos (2014) por los atropellos del Estado chileno al pueblo indígena mapuche, particularmente, por el caso denominado Norín Catrimán y otros; o póngase atención en que desde hace diecisiete años lugares popularmente significativos y cargados de una emblemática memoria política, como la población La Legua de Santiago de Chile, viven una intervención estatal, justificada por la presencia del narcotráfico, que prontamente se convirtió en "bastante más que una serie de hechos aislados de abuso policial y que, siendo en realidad un patrón de violencia, responde a su vez a ciertos arreglos institucionales que favorecen su perpetuación" (Cortés, Delgado y García, 2017, p. 87). Los derechos humanos continúan violándose en Chile en la medida que los instrumentos y prácticas que podrían contribuir a su despliegue quede confinada a una estricta visión jurídica, de carácter punitivo o quede atrapada por la retórica que los hace exclusivos a contextos totalitarios o represivos extirpando su dimensión y sentido.

Desde una perspectiva mundial, el impacto que a muchas personas de todo el planeta sensibiliza, y con razón, en complicidad por el dolor de los asesinados por el terrorismo fundamentalista religioso en muchos lugares, debería ser consistente con una educación que no pasa necesariamente por ninguna escuela, pero que hace de los procesos formativos provenientes de ella un lugar desde donde brota la indignación ética que provoca que con la misma fuerza enojada que hace reprobar esas acciones, se reprueben también los actos de aquellos lugares del globo, los llamados países del primer mundo, que hacen de sus históricas y estructurales ventajas comparativas, motivo de poder impune no obstante revestirse de demócratas y de paladines de los derechos humanos. En suma, una educación basada en una cultura de derechos humanos podría estar atenta, en cuerpo y alma, en cada lugar de la tierra, sobre cada sistema, que desprecie el valor de la vida.

Una cultura de derechos humanos abona valor al desarrollo integral de un país, a la responsabilidad y al respeto por las personas, otorga legitimidad moral y principios de justicia social a los objetivos del desarrollo humano. Desde ahí la educación juega un rol fundamental para entender que es el amparo que cobija su fuerza sobre todo cuando se sabe, como se ha dicho en los párrafos precedentes, que en muchos lugares de la patria-mundo el estado de derecho, fundamento de la vida democrática, se encuentra en condiciones tan precarias, que eso que llaman soberanía se vuelve ilusión. En materia de derechos humanos no hay una jerarquía valórica, tocar uno, como quien toca un ser humano, toca todo lo que hay en él. Por eso cada eslabón que permita dignificar lo humano es un paso a vivir otorgándole contenido, sentido y belleza a la vida vivida, a la vida por vivir.

Está reflexión entre educación y derechos humanos podría desembocar a restablecer un camino de esta trayectoria histórica, que, entre otras cosas, no confunda el dolor de las víctimas con los contenidos que dan definición a los derechos humanos y la relevancia de la verdad y la justicia. Se trata de otorgar herramientas soberanas, de instituciones y políticas pertinentes, se trata de integrar de verdad, en serio, los derechos humanos como expresión de soberanía y/o garante a la vez de esa soberanía.

La idea que para ser alguien en la vida no importa el costo parece tener adhesión en un mundo regido por las coordenadas sistémicas actuales. Esto parece incrustado en muchas personas, independiente de la generación y del origen sociocultural. Nadie está exento, quizá empresarios, políticos y ex militares solo lideren esa pulsión. No obstante:

Es importante subrayar que la escuela en América Latina ha jugado un rol en la vida pública que fue y sigue siendo fundamental. ...La escuela fue y es, además de un espacio de transmisión y recreación de la cultura, un lugar de integración social, un nodo comunitario (Dussel, 2015, p.75).

La educación y los derechos humanos podrían ser claves no solo para no desmoronar las utopías, sino como un lugar donde la búsqueda de sentidos sean amparados con la alteridad fundamental que enriquece a una sociedad por su diversidad en la tolerancia.

Entonces la soledad del ser humano se vuelve latencia. Ortega y Gasset (1936) hablaba del impulso vocacional, y del congelamiento moral: 
Es inevitable: hacia los treinta años, en medio de los fuegos juveniles que perduran, aparece la primera línea de nieve y congelación sobre las cimas de nuestra alma. Llegan a nuestra experiencia las primeras noticias directas del frío moral. Un frío que no viene de fuera, sino que nace de lo más íntimo (...) Por esto, es la edad en que dejamos de ser lo que nos han enseñado, lo que hemos recibido en la familia, en la escuela, en el lugar común de nuestra sociedad. Nuestra voluntad gira en redondo (p. 93).

El mismo Ortega y Gasset (1936) habla, sin embargo, de un fondo insobornable. Pues bien, la educación en clave de derechos humanos podría aportar peso específico para que ese fondo insobornable sea parte íntegra del cultivo cotidiano de la vida. Byung Chul Han (2016) va en el mismo sentido cuando se refiere a la etización del poder, "A diferencia de la pura violencia, que no permitiría ningún asentimiento ni ninguna negativa, es decir ninguna elección...la relación de poder encierra la posibilidad de la resistencia” (p. 157).

\section{Conclusión}

Educación y derechos humanos están unidos por una visión panorámica en donde los quiebres y continuidades, con sus sedimentos e insistencias, se van incrustando en los pliegues sociales, políticos y económicos de Chile. El ensayo dio cuenta de una sociedad que desde el golpe cívico-militar de 1973 y de la instalación del sistema neoliberal, hizo que la vida de sus habitantes cambiara profundamente, entre otras cosas porque lo que cambió fue la estructura con la cual regía la sociedad y funcionaba el sistema, en el mismo momento en que los cuerpos y los derechos humanos eran transgredidos.

En ese contexto la educación se mercantilizó y tanto su acceso como su calidad han sido puestos en tensión en relación con los cambios y perspectivas que Chile ha realizado, pues en el fondo la educación es un campo de disputa permanente, que afecta los sentidos y sensibilidades de la sociedad. De ahí, el valor de las pequeñas causas y de la cotidianidad - esa que muchas veces es parida desde el aula y desde la relación profesor-alumno - se resintió por el miedo y la carencia de orientaciones en medio de los cambios. Desde ahí la convocatoria por rearticular la sinérgica relación educación y derechos humanos, acentuando el valor y compromiso que tiene lo ético.

El ensayo demostró que los derechos humanos son un tema incómodo para países, que como Chile, aún se debe plena verdad y justicia. Se asume sin embargo que seguirá siendo de esa manera, sí se confunde su sentido y profundidad exclusivamente con el pasado o con la pertenencia de dolor de un solo grupo humano determinado. Los derechos humanos son un tema y una opción, plausible de comprender y allanar, con la sensibilidad crítica necesaria, en la medida que en conjunto con la educación asumen éticamente caminos.

Finalmente, resulta claro que las interpelaciones y desafíos que la educación y los derechos humanos tienen son más diversos y profundos de lo que este ensayo dice. Se avizoran nuevas temáticas y nuevas perspectivas reflexivas, investigativas y de análisis hacía fronteras conceptuales y epistémicas por incursionar o por seguir trabajando. Las paradojas del continente, la emergencia de los pueblos originarios, la permanente interrogante por la identidad, las relaciones de género, la vivencia de los cuerpos, los lazos de pertenencia son, cada una por si sola y en conjunto, contenidos riquísimos que configuran parte de los pliegues con que la educación y los derechos humanos se constituye y debate hoy en cada una de las sociedades de América Latina.

\section{REFERENCIAS}

Aylwin, P. (1992). La transición chilena. Discursos escogidos marzo 1990-1992. Santigo, Chile: Ándres Bello. Bourdieu, P. y Passeron, J. (2006). Los herederos, Los estudiantes y la cultura. Buenos Aires, Argentina: Siglo XXI. Bourdieu, P. (2014). Capital cultural, escuela y espacio social. Buenos Aires, Argentina: Siglo XXI.

Comisión Nacional de Verdad y Reconciliación. (1991). Informe de la Comisión Nacional de Verdad y Reconciliación. Santiago, Chile: Ministerio Secretaría General de Gobierno. 
Comisión Nacional sobre Prisión Política y Tortura. (2005). Informe de la Comisión Nacional Sobre Prisión Politica y Tortura. Santiago, Chile: Ministerio Secretaría General de Gobierno.

Constitución Política de la República de Chile. (2005). Texto fundido. Recuperado de http://www.leychile.cl/ Navegar?idNorma $=242302$

Corte Interamericana de Derechos Humanos. (2014). Caso Norín Catrimán y otros. Recuperado de http:// www.corteidh.or.cr/docs/casos/articulos/seriec_279_esp.pdf

Cortés, P., Delgado, J. y García Campo, G. (2017). A quince años de intervención estatal violencia policial en la población La Legua. Santiago, Chile: Clínica de interés público y Derechos Humanos UDP. Comité de Defensa y Promoción de Derechos Humanos de La Legua.

Dussel, I. (2015). Deudas y desafíos de una nueva agenda en educación. Nueva Sociedad. Democracia y política en América Latina, 257, 66-76.

Freire, P. (2014). Pedagogía de la indignación. Cartas pedagógicas en un mundo revuelto. Buenos Aires, Argentina: Siglo XXI.

Han, B. C. (2016). Sobre el poder. Barcelona, España: Herder.

Kremerman, M. (2009). Radiografía del financiamiento de la educación chilena: diagnóstico, análisis y propuestas. Recuperado de https://goo.gl/tsCwWb

Lechner, N. (2006). Obras escogidas 1. Santiago de Chile: Lom.

Maturana, H. (1997). Emociones y lenguaje en educación y politica (9a ed.). Santiago, Chile: Dolmen.

Marshall, T. (1992). Citizenship and Social Class. [Ciudadanía y clase social]. London, England: Pluto Press.

Meuss, J., González, R. y Manzi, R. (2016). Ser blanco o moreno en Chile: El impacto de la apariencia en las expectativas educativas y las calificaciones escolares. En J. García, y R. Manzi (eds.). Abriendo las puertas del aula. Transformación de las prácticas docentes. pp. 515-542. Santiago, Chile: Universidad Católica de Chile.

Ordaz, P. (2014, 27 de noviembre). La cultura es la capacidad crítica de no creerse el centro del mundo. El País, sección Cultura. Recuperado de https://elpais.com/cultura/2014/11/27/actualidad/1417125974_227525.html

Organización de Nacional Unidas [ONU]. (1948). Declaración Universal de Derechos Humanos. Recuperado de http://www.un.org/es/universal-declaration-human-rights/

Ortega, E., y Güell, P. (Coords.). (2004). Desarrollo humano en Chile, elpoder: ¿para quéy para quién?, Santiago, Chile: PNUD

Ortega y Gasset, J. (1936). El Espectador, Tomo I. Santiago, Chile: Extra.

Osorio, J. (2003). Educación en derechos humanos. Persona y sociedad, 3 (17), 193-208.

Oyarzún, J. (2017). ¿Valor agregado? Reflexión sobre el fundamento en que descansa nuestro valor como humanidad. En P. Achondo y P. Álvarez (Coords.), Si estos callan, las piedras gritarán (Lc 19, 40), ensayos de teología práctica interdisciplinar. (pp. 101-117). Santiago, Chile: Lom.

Parra, N. (1992). Ya no sueño. En Pichanga, profecias a falta de ecuaciones. Recuperado de https://bit.ly/2EqTnTi

Programa de las Naciones Unidas para el Desarrollo [PNUD]. (2004). La democracia en América Latina. Buenos Aires, Argentina: Taurus.

Salazar, G. (1988). Los dilemas históricos de la auto-educación popular en Chile ęintegración o autonomía relativa?. Proposiciones, 15, 84-129.

Silva, I. (2017). Formación docente para la justicia social en un Chile desigual. En Silva, Ilich., Diniz, Julio., Zeichner, Ken. Justicia social. La dimensión olvidada de la formación docente. (pp. 121-144). Santiago, Chile: Mutante.

Stern, S. (2009). Recordando el Chile de Pinochet. En visperas de Londres. Santiago, Chile: Universidad Diego Portales. Tedesco, J. (2000). Educar en la sociedad del conocimiento. México: Fondo de Cultura Económica. 
Paulo Álvarez-Bravo. Educación y derechos humanos en Chile, una relación necesaria [1]

\section{Notas}

[1] Muchas de las ideas de este ensayo, surgieron de la invitación que los profesores Jesús Lara y Sebastián Valenzuela extendieron al autor para participar en "el ciclo de charlas" en torno a la educación, organizado en la Universidad Austral de Chile, en diciembre de 2015.

\section{BY-NC-ND}

